\title{
Proteção fetal contra o vírus da diarréia viral bovina (BVDV) em vacas prenhes previamente imunizadas com uma vacina experimental atenuada ${ }^{1}$
}

\author{
Sandra Arenhart ${ }^{2}$, Letícia Frizzo da Silva² ${ }^{2}$ Andréia Henzel ${ }^{2}$, Rogério Ferreira ${ }^{3}$, \\ Rudi Weiblen ${ }^{2}$ e Eduardo Furtado Flores ${ }^{2^{*}}$
}

\begin{abstract}
Arenhart S., Silva L.F., Henzel A., Ferreira R., Weiblen R. \& Flores E.F. 2008. [Fetal protection against bovine viral diarrhea virus (BVDV) in pregnant cows previously immunized with an experimental attenuated vaccine.] Proteção fetal contra o vírus da diarréia viral bovina (BVDV) em vacas prenhes previamente imunizadas com uma vacina experimental atenuada. Pesquisa Veterinária Brasileira 28(10):461-470. Departamento de Medicina Veterinária, Centro de Ciências Rurais, Universidade Federal de Santa Maria, 97105-900, Santa Maria, RS, Brazil. E-mail: flores@ccr.ufsm.br

This paper reports the antibody response and fetal protection in pregnant cows conferred by an experimental vaccine containing two attenuated strains of bovine viral diarrhea virus (BVDV-1 and BVDV-2). Cows $(n=19)$ were vaccinated twice, with a 34days-interval, with the experimental vaccine and together with non-vaccinated controls $(n=18)$, were mated and challenged between days 60 and 90 of gestation by intranasal inoculation of four heterologous BVDV-1 and BVDV-2 isolates. The antibody response was evaluated by serum-neutralization tests performed at different intervals after vaccination (days 34, 78 and 138 post-vaccination [pv]). Fetal protection was monitored by ultrassonographic and clinical examination of the dams and fetuses during the rest of gestation; and through virological and serological examination of pre-colostral blood obtained from aborted and/or recently born fetuses/calves. At the day of challenge (day $138 \mathrm{pv}$ ), all vaccinated cows had neutralizing antibodies in high titers against BVDV-1 $(1,280-\geq 10,240)$, and with one exception (titer 20), presented moderate to high titers to BVDV-2 $(80-1,280)$. At the end of the monitoring, only three out of 18 control cows (16.6\%) delivered healthy, virus-free calves. Fifteen non-vaccinated cows $(83.3 \%)$ presented signs of fetal infection and/or had reproductive losses. Seven of these cows $(38.8 \%)$ delivered virus-positive calves; five were healthy and survived $(27.7 \%)$; two were premature or weak and lasted three and 15 days, respectively. The other eight cows (44.4\%) aborted between day 30 post-challenge and the parturition; or delivered premature or stillbirth calves. In contrast, 17 out of $19(89.4 \%)$ vaccinated cows delivery virus-free, healthy calves. One vaccinated cow aborted around day 130 post-challenge, yet this fetus could not be examined for the presence of virus. Another cow delivered a virus-positive calf (5.2\%). In summary, the experimental vaccine induced adequate antibody titers in most animals and the immunological response induced by vaccination was able to prevent fetal infection and reproductive losses upon challenge with a pool of heterologous BVDV isolates. Hence, this experimental vaccine may be
\end{abstract}

${ }^{1}$ Recebido em 4 de abril de 2008.

Aceito para publicação em 25 de abril de 2008.

Parte da Dissertação de Mestrado da primeira autora, no Programa de Pós-Graduação em Medicina Veterinária, Universidade Federal de Santa Maria (UFSM).

\footnotetext{
2 Setor de Virologia, Departamento de Medicina Veterinária Preventiva, UFSM, Santa Maria, RS 97105-900, Brasil. *Autor para correspondência: flores@ccr.ufsm.br

${ }^{3}$ Departamento de Clínica de Grandes Animais, UFSM, Santa Maria, RS.
} 
an attractive alternative for the prevention of reproductive losses associated with BVDV infection.

INDEX TERMS: Bovine viral diarrhea virus, BVDV, experimental vaccine, fetal protection.

RESUMO.- Esse artigo relata a avaliação da resposta sorológica e proteção fetal conferida por uma vacina experimental contendo duas amostras atenuadas do vírus da diarréia viral bovina tipos 1 (BVDV-1) e 2 (BVDV-2). Vacas foram imunizadas com a vacina experimental $(n=19)$ e juntamente com controles não-vacinadas $(n=18)$ foram colocadas em cobertura e desafiadas, entre os dias 60 e 90 de gestação, pela inoculação intranasal de quatro amostras heterólogas de BVDV-1 e BVDV-2. A resposta sorológica foi avaliada por testes de soro-neutralização realizados a diferentes intervalos após a vacinação (dias 34, 78 e 138 pós-vacinação [pv]). A proteção fetal foi monitorada por exames ultra-sonográficos e clínicos realizados durante o restante da gestação; e pela pesquisa de vírus e anticorpos no sangue pré-colostral coletado dos fetos abortados e/ou dos bezerros recém nascidos. No dia do desafio (dia $138 \mathrm{pv}$ ), todas as vacas vacinadas apresentavam anticorpos neutralizantes em títulos altos contra o BVDV-1 (1.280- $\geq 10.240)$ e, com exceção de uma vaca (título 20), todas apresentavam títulos médios a altos contra o BVDV-2 (80-1.280). O monitoramento da gestação revelou que, dentre as 18 vacas não-vacinadas, apenas três $(16,6 \%)$ pariram bezerros saudáveis e livres de vírus. As 15 restantes $(83,3 \%$ ) apresentaram indicativos de infecção fetal e/ou falhas reprodutivas. Sete dessas vacas $(38,8 \%)$ pariram bezerros positivos para o vírus, sendo que cinco eram saudáveis e sobreviveram (27,7\%); e dois apresentavam sinais de prematuridade ou fraqueza e morreram três e 15 dias após o nascimento, respectivamente. As oito vacas controle restantes $(44,4 \%)$ abortaram entre o dia 30 pós-desafio e às proximidades do parto, ou deram à luz bezerros prematuros, inviáveis ou natimortos. Por outro lado, 17 de 19 (89,4\%) vacas vacinadas deram à luz bezerros saudáveis e livres de vírus. Uma vaca vacinada abortou 130 dias pós-desafio, mas o produto não pôde ser examinado para a presença de vírus. Outra vaca vacinada pariu um bezerro positivo para o vírus $(5,2 \%)$. Em resumo, a vacina experimental induziu títulos adequados de anticorpos na maioria dos animais; e a resposta imunológica induzida pela vacinação foi capaz de conferir proteção fetal e prevenir as perdas reprodutivas frente ao desafio com um pool de amostras heterólogas de BVDV. Assim, essa vacina experimental pode representar uma boa alternativa para a redução das perdas reprodutivas associadas com a infecção pelo BVDV.

TERMOS DE INDEXAÇÃO: Vírus da diarréia viral bovina, BVDV, vacina experimental, proteção fetal.

\section{INTRODUÇÃO}

O vírus da diarréia viral bovina (Bovine viral diarrhea virus, BVDV) é um dos patógenos mais importantes de bovi- nos, responsável por grandes perdas econômicas para a pecuária bovina em todo mundo (Baker 1995). O BVDV é um vírus envelopado, com $45 \mathrm{~nm}$ de diâmetro, genoma RNA de fita simples com $12,5 \mathrm{~kb}$, classificado na família Flaviviridae, gênero Pestivirus (Horzinek 1991). Os pestivírus podem ser classificados em citopatogênicos (CP) e não-citopatogênicos (NCP), de acordo com o efeito da replicação viral em células de cultivo (Lindebach \& Rice 2001). Uma característica marcante entre isolados de campo do BVDV é a grande diversidade antigênica e a existência de dois genótipos genética e antigenicamente distintos: BVDV tipos 1 e 2 (BVDV-1 e BVDV-2) (Pellerin et al. 1994).

A infecção de animais susceptíveis pelo BVDV pode produzir uma variedade de manifestações, que incluem desde infecções subclínicas, doença respiratória, digestiva, reprodutiva, a doença das mucosas (DM), síndrome hemorrágica (SH) e imunodepressão (Baker 1995). As maiores perdas parecem resultar da infecção de fêmeas prenhes, podendo ocorrer reabsorção embrionária, abortos, mumificações, natimortalidade, malformações fetais, nascimento de bezerros fracos, persistentemente infectados (PI) e imunotolerantes ao vírus (Grooms et al. 2007). A infecção fetal com amostras NCP entre os dias 45 e 125 de gestação freqüentemente resulta na produção de bezerros PI imunotolerantes, provavelmente devido à deleção de clones de linfócitos B e T reativos contra antígenos do vírus infectante (McClurkin et al. 1984). Com isso, os animais PI são incapazes de responder imunologicamente contra o vírus infectante e também contra amostras de BVDV antigenicamente muito semelhantes. Assim, os animais PI replicam e excretam o vírus durante toda a vida, constituindo-se no principal reservatório do vírus (Houe 1995).

O controle da infecção pelo BVDV baseia-se na identificação e eliminação dos animais $\mathrm{PI}$, associados ou não com o uso de vacinas (Bolin 1995). As vacinas devem proteger os animais da doença clínica e principalmente impedir a transmissão transplacentária e a infecção fetal (Van Oirschot et al. 1999). Atualmente existem dois tipos principais de vacinas contra o BVDV: as vacinas inativadas e as vacinas vivas modificadas (Van Oirschot et al. 1999, Fulton et al. 2003). As vacinas inativadas são formuladas com uma ou mais cepas do vírus, geralmente induzem níveis moderados de anticorpos, e necessitam de várias aplicações, além de reforços anuais. A maioria das vacinas vivas contém amostras $\mathrm{CP}$, atenuadas in vitro por sucessivas passagens em cultivo celular, associados ou não com mutagênese química (Bolin 1995). Essas vacinas geralmente produzem imunidade mais sólida e duradoura, porém não devem ser administradas a fêmeas prenhes (Bolin 1995, Van Oirschot et al.1999).

Nas últimas duas décadas, um número de diferentes 
formulações vacinais, incluindo vacinas inativadas e atenuadas, vacinas recombinantes e de subunidades, além de protocolos alternativos de vacinação e desafio, têm sido avaliados na tentativa de se aumentar a eficácia das vacinas, sobretudo em relação à proteção fetal (Brownlie et al. 1995, Cortese et al. 1998, Bruschke et al. 1999, Beer et al. 2000, Kovács et al. 2003, Fairbanks et al. 2004, Brock et al. 2006, Ellsworth et al. 2006, Ficken et al. 2006, Grooms et al. 2007). Não obstante esses esforços, nenhuma vacina testada até o presente foi capaz de conferir total proteção aos fetos, o que representa um obstáculo para o efetivo controle da infecção pelo uso da vacinação (Kelling 2004).

A infecção pelo BVDV está amplamente difundida no rebanho bovino brasileiro, e amostras de ambos os genótipos e com diferenças genéticas e antigênicas das cepas americanas já foram identificadas no país (Flores et al. 2002, 2005, Cortez et al. 2006). Essa diversidade genética e antigênica possui implicações práticas para o diagnóstico, produção de vacinas e estratégias de controle da enfermidade (Flores et al. 2005). Estudos avaliando a resposta sorológica conferida por vacinas comerciais disponíveis no mercado brasileiro revelaram a incapacidade dessas vacinas em induzirem proteção fetal ou mesmo títulos de anticorpos neutralizantes adequados em ovinos (Vogel et al. 2001, 2002) e bovinos (Lima et al. 2005). No intuito de produzir uma vacina mais efetiva, Brum et al. (2002) demonstraram que duas amostras de BVDV atenuadas por métodos tradicionais foram capazes de induzir resposta sorológica de amplo espectro e induziram proteção fetal em ovelhas prenhes. Essas mesmas amostras demonstraram ser suficientemente atenuadas e induziram boa resposta sorológica em bovinos (Lima et al. 2004).

O objetivo do presente estudo foi avaliar a capacidade dessa vacina experimental atenuada em conferir proteção fetal contra o BVDV em vacas prenhes. Para isso, vacas prenhes previamente imunizadas ou não, foram desafiadas com amostras heterólogas de vírus e submetidas ao monitoramento da gestação. A avaliação da proteção fetal considerou o status clínico, virológico e sorológico dos fetos e bezerros recém-nascidos.

\section{MATERIAL E MÉTODOS \\ Delineamento experimental \\ Vacas soronegativas ao BVDV foram imunizadas duas vezes} com uma vacina experimental atenuada (Brum et al. 2002). Juntamente com um grupo de vacas não imunizadas, foram colocadas em cobertura e, trinta dias após o final do período de monta, foram submetidas ao diagnóstico de gestação. Trinta e sete vacas prenhes, dos grupos vacinados e controles, foram selecionadas para o teste de proteção vacinal. Esses animais foram desafiados, entre os dias 60 e 90 de gestação, pela inoculação intranasal de uma suspensão contendo quatro amostras de campo do BVDV. A eficácia da vacina foi avaliada pela mensuração dos títulos de anticorpos neutralizantes produzidos pelos animais vacinados; e pela capacidade de proteger os fetos da infecção viral. A viabilidade fetal foi investigada por palpação retal e por ultra-sonografia (US), realizados a diferentes intervalos após o desafio. A proteção fetal foi também avaliada pela pesquisa de vírus e anticorpos nos bezerros abortados e/ou recém-nascidos. O delineamento experimental está ilustrado na Figura 1.

\section{Células e vírus}

Os procedimentos de amplificação, quantificação e isolamento viral; e os testes de soroneutralização (SN) foram realizados em células de rim bovino MDBK (Madin Darby bovine kidney, American Type Culture Collection [ATCC] CCL-22) livres de pestivírus. As células foram cultivadas em meio essencial mínimo (MEM), contendo penicilina $\left(1,6 \mathrm{mg}^{\mathrm{mL}} \mathrm{mL}^{-1}\right)$, estreptomicina $\left(0,4 \mathrm{mg} \mathrm{mL}^{-1}\right)$ e fungizona $\left(25 \mathrm{mg} \cdot \mathrm{mL}^{-1}\right)$; suplementado com $10 \%$ de soro eqüino. As amostras parentais dos vírus vacinais BVDV1 (IBSP-2) e BVDV-2 (VS-253) citopáticas foram gentilmente cedidas pela Dra. Edviges Maristela Pituco (Instituto Biológico de São Paulo, São Paulo, SP) e pelo Dr. Ruben Donis (University of Nebraska, Lincoln, USA), respectivamente. O procedimento utilizado para obtenção das amostras vacinais atenuadas foi descrito anteriormente por Brum et al. (2002). No presente estudo, foram utilizadas amostras dos vírus obtidas na passagem 30 (p30) do trabalho original de obtenção das cepas vacinais. As amostras utilizadas no desafio são isolados brasileiros NCPs, pertencentes ao genótipo BVDV-1 (SV-126.8 e UFSM-1) e genótipo BVDV-2 (SV-63 e SV-260) (Flores et al. 2005, Cortez et al. 2006).

\section{Animais, imunização e desafio}

Foram utilizadas 80 vacas de raça mista, com idade entre três e cinco anos, soronegativas para o BVDV. Quarenta animais

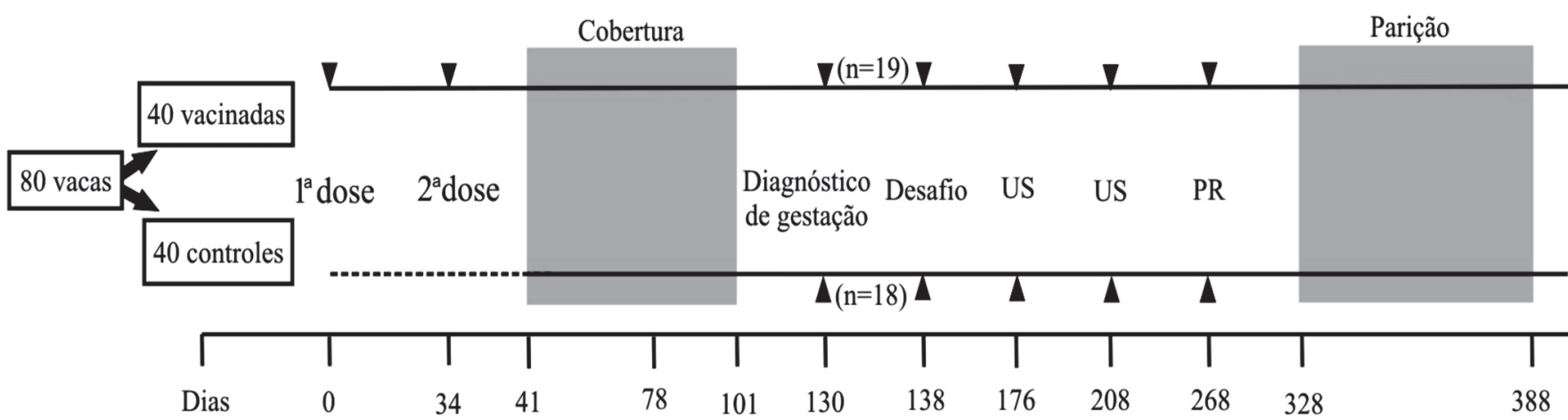

Fig.1. Delineamento experimental. Grupos de vacas vacinadas ou controles foram colocados em cobertura e posteriormente desafiadas com uma suspensão contendo quatro amostras heterólogas de BVDV. A gestação foi monitorada por ultra-sonografia (US) e palpação retal (PR). O status clínico, virológico e sorológico dos recém-nascidos foi avaliado por ocasião do parto. 
foram imunizados e quarenta permaneceram como controles, não-vacinados. Os animais foram imunizados duas vezes, com intervalo de 34 dias, pela via intramuscular (IM). Na primeira imunização, receberam $10^{7,2}$ DICC $_{50}$ (doses infectantes para $50 \%$ dos cultivos $/ \mathrm{mL}$ ) da cepa IBSP-2 e $10^{7,4}$ DICC $_{50}$ da cepa VS-253. Os animais controle foram inoculados com o mesmo volume de meio essencial mínimo. Aos 34dpv, os animais receberam uma segunda imunização com $10^{6,77} \mathrm{DICC}_{50}$ da cepa IBSP-2 e 107,0 DICC 50 da cepa VS-253. Sete dias após a segunda imunização, as vacas foram colocadas em cobertura por um período de 60 dias. Aproximadamente trinta dias após o final do período de monta realizou-se exame ultra-sonográfico (US) para o diagnóstico de gestação. A partir desse exame, foram agrupados aleatoriamente 19 animais prenhes no grupo vacinal e 18 vacas prenhes no grupo controle.

No dia 138 pós-vacinação (dpv), correspondente aos dias 60-90 dias de gestação, os animais dos grupos vacinado e controle foram desafiados. O desafio foi realizado pela inoculação de uma suspensão viral contendo $1^{6,9}$ DICC $_{50}$ (SV126.8), $10^{6,9}$ DICC $_{50}$ (UFSM-1), 106,7 DICC $_{50}$ (SV-63) e 10 10,7 DICC $_{50}$ (SV-260), amostras de BVDV isoladas no Brasil, pela via intranasal (IN), em uma dose total de $10^{7,1} \mathrm{DICC}_{50}$.

\section{Monitoramento da gestação}

Após o desafio, a gestação foi monitorada por palpação retal e por US nos dias 176 e 208dpv; e por palpação retal no dia 268dpv. Esses exames tinham por finalidade avaliar a viabilidade dos fetos nos meses que se seguiram ao desafio. No restante da gestação, as vacas foram monitoradas diariamente, em busca de sinais que indicassem abortamento e/ou distúrbios gestacionais. Os fetos abortados foram submetidos a exame macroscópico e coleta de material para exames com a maior brevidade após a ocorrência dos abortos.

Nas proximidades do final previsto da gestação, os partos foram induzidos pela administração de dexametasona (Azium Solução, Shering-Plough, SP, Brasil; 20mg por animal) e cloprostenol sódico (Ciosin, Shering-Plough, SP, Brasil; 0,53mg por animal) em dose única. Para isto, os animais eram divididos em grupos, de acordo com a idade gestacional estimada pela data de cobertura e pela palpação retal. Os animais assim tratados foram monitorados por um período de $48 \mathrm{~h}$, até a ocorrência do parto.

Os bezerros recém-nascidos eram assistidos e examinados clinicamente. Amostras de sangue e soro pré-colostral foram coletadas desses animais para a pesquisa de vírus e de anticorpos, respectivamente.

\section{Sorologia}

As amostras de soro coletadas das vacas a diferentes intervalos pós-vacinação e desafio, e dos bezerros recém-nascidos, foram submetidas a testes de soroneutralização (SN), com algumas modificações na metodologia utilizada por Botton et al. (1998). Foram utilizadas diluições crescentes de soro, partindo de 1:5 até 1:10.240, frente a doses constantes dos vírus homólogos (100-200 DICC $_{50}$ ) utilizando-se células MDBK como indicador da replicação viral. A resposta sorológica foi avaliada nos dias $34,78,138$ pós-vacinação (dpv), e novamente 38 dias após o desafio. O título neutralizante foi considerado a recíproca da maior diluição do soro capaz de neutralizar a replicação viral. As médias dos títulos de anticorpos neutralizantes foram calculadas em títulos médios geométricos (GMT), conforme Thrusfield (1986). Também realizou-se a sorologia de amostras de soro pré-colostral colhidas dos bezerros dos grupos controle e vacinal. O soro dos bezerros foi novamente testado para a presença de anticorpos neutralizantes entre 30 e 60 dias após o nascimento. Todas as amostras de soro foram testadas para a presença de anticorpos neutralizantes contra os vírus dos genótipos BVDV-1 (IBSP2) e BVDV-2 (VS-253).

\section{Pesquisa de vírus}

As amostras de sangue pré-colostral (colhidas com EDTA a $10 \%$ ) obtidas dos bezerros recém-nascidos dos grupos controle e vacinal foram submetidas à pesquisa de vírus. $\mathrm{O}$ isolamento viral foi realizado em células MDBK cultivadas em placas de seis cavidades. Previamente à inoculação, procedeu-se a separação da capa flogística utilizando-se um tampão de lise de hemácias (155mM NH $\mathrm{m}_{4} \mathrm{Cl}, 10 \mathrm{mM} \mathrm{KHCO}_{3}, 1 \mathrm{mM}$ EDTA, pH 7,4), adicionado em volume 2,5 vezes o volume da amostra, seguido de centrifugação (1000 x g por $5 \mathrm{~min})$. Os leucócitos assim separados foram ressuspendidos em $0,5 \mathrm{~mL}$ de MEM e inoculados em monocamadas de células MDBK. Os cultivos foram monitorados por três passagens consecutivas de $72 \mathrm{~h}$ cada. Ao final da terceira passagem, as células inoculadas foram submetidas à imunofluorescência (IFA) para a detecção de antígenos virais, de acordo com metodologia descrita por Botton et al. (1998). Para confirmar o status de infecção persistente, os animais foram testados novamente para a presença de vírus no sangue com, aproximadamente, 30 dias de idade.

\section{RESULTADOS}

\section{Resposta sorológica}

Os títulos individuais de anticorpos neutralizantes desenvolvidos contra os vírus homólogos após a vacinação estão apresentados no Quadro 1. A evolução sorológica dos títulos médios geométricos (GMTs) dos anticorpos nos grupos vacinado e controle está apresentada na Figura 2. Após a primeira imunização (34dpv), os títulos atingiram valores medianos a altos, principalmente frente ao BVDV-1 (títulos entre 1.280 e 5.120); e títulos baixos a médios frente ao BVDV-2 (entre 5 e 160). O teste do soro coletado no dia 78 pv após a revacinação demonstrou um aumento nos títulos frente ao BVDV-2 (entre 20 e 1.280), enquanto que os títulos contra o BVDV-1 não apresentaram grande variação após a revacinação (entre 640 e 5.120) (Quadro 1, Figura 2).

No dia do desafio (138dpv), todas as vacas vacinadas apresentavam anticorpos neutralizantes em títulos altos contra o BVDV-1, amostra IBSP-2 (1.280- $\geq 10.240)$. Com exceção de uma vaca (título 20), todas as vacas também apresentavam títulos médios a altos contra o BVDV-2, amostra VS-253 (80-1.280). Após o desafio, outro aumento nos níveis de anticorpos foi observado, com os títulos atingindo valores entre 5.120 e 10.240 para o BVDV-1; e entre 160 e 10.240 para o BVDV-2 (Quadro 1, Figura 2). Os animais do grupo controle permaneceram soronegativos até o dia do desafio. No dia 38 pós-desafio (176dpv) todos os animais do grupo controle, apresentavam títulos de anticorpos para o BVDV-1 (1.280-5.120) e para o BVDV-2 (160-5.120). 
Quadro 1. Títulos de anticorpos neutralizantes no soro de vacas imunizadas com uma vacina experimental atenuada contra o vírus da diarréia viral bovina (BVDV)a

\begin{tabular}{|c|c|c|c|c|c|c|c|c|c|c|}
\hline \multirow[t]{3}{*}{ Animal no. } & \multicolumn{6}{|c|}{ Dias pós-vacinação } & \multicolumn{4}{|c|}{ Dias pós-desafio } \\
\hline & \multicolumn{2}{|c|}{$0^{\mathrm{b}}$} & \multicolumn{2}{|c|}{$34^{\mathrm{C}}$} & \multicolumn{2}{|c|}{78} & \multicolumn{2}{|c|}{$0(138 d p v)^{d}$} & \multicolumn{2}{|c|}{38 (176dpv) } \\
\hline & IBSP-2 & VS-253 & IBSP-2 & VS-253 & IBSP-2 & VS-253 & IBSP-2 & VS-253 & IBSP-2 & VS-253 \\
\hline \multicolumn{11}{|l|}{$\begin{array}{c}\text { Vacinados } \\
\quad(n=19)\end{array}$} \\
\hline 3 & $<5$ & $<5$ & 1.280 & 40 & 5.120 & 320 & 5.120 & 640 & $\geq 10.240$ & 1.280 \\
\hline 5 & $<5$ & $<5$ & 1.280 & 10 & 2.560 & 320 & $\geq 10.240$ & 160 & $\geq 10.240$ & $\geq 10.240$ \\
\hline 10 & $<5$ & $<5$ & 5.120 & 80 & 2.560 & 1.280 & $\geq 10.240$ & 640 & 5.120 & 1.280 \\
\hline 12 & $<5$ & $<5$ & 5.120 & 20 & $n t^{e}$ & nt & 1.280 & 160 & 5.120 & 1.280 \\
\hline 16 & $<5$ & $<5$ & 1.280 & 40 & 2.560 & 320 & 5.120 & 320 & $\geq 10.240$ & 160 \\
\hline 17 & $<5$ & $<5$ & 2.560 & 40 & 1.280 & 320 & 5.120 & 160 & $\geq 10.240$ & 5.120 \\
\hline 19 & $<5$ & $<5$ & 1.280 & 80 & 5.120 & 160 & $\geq 10.240$ & 640 & $\geq 10.240$ & 5.120 \\
\hline 22 & $<5$ & $<5$ & 5.120 & 40 & 5.120 & 640 & 5.120 & 320 & $\geq 10.240$ & 2.560 \\
\hline 23 & $<5$ & $<5$ & 2.560 & 160 & 2.560 & 640 & 5.120 & 1.280 & $\geq 10.240$ & 5.120 \\
\hline 28 & $<5$ & $<5$ & 1.280 & 40 & 5.120 & 320 & $\geq 10.240$ & 1.280 & $\geq 10.240$ & 5.120 \\
\hline 31 & $<5$ & $<5$ & 2.560 & 20 & 1.280 & 40 & 5.120 & 80 & 5.120 & 1.280 \\
\hline 32 & $<5$ & $<5$ & 5.120 & 80 & 1.280 & 320 & 2.560 & 640 & 5.120 & 2.560 \\
\hline 33 & $<5$ & $<5$ & 2.560 & 20 & 1.280 & 160 & $\geq 10.240$ & 80 & $\geq 10.240$ & $\geq 10.240$ \\
\hline 35 & $<5$ & $<5$ & 1.280 & 20 & 2.560 & 80 & 5.120 & 20 & $\geq 10.240$ & 5.120 \\
\hline 38 & $<5$ & $<5$ & 2.560 & 20 & 5.120 & 160 & $\geq 10.240$ & 160 & $\geq 10.240$ & 2.560 \\
\hline 40 & $<5$ & $<5$ & 5.120 & 160 & 2.560 & 80 & 5.120 & 160 & 5.120 & $\geq 10.240$ \\
\hline 45 & $<5$ & $<5$ & 2.560 & 5 & 2.560 & 80 & 2.560 & 320 & 5.120 & 2.560 \\
\hline 48 & $<5$ & $<5$ & 2.560 & 5 & 5.120 & 320 & 5.120 & 320 & $\geq 10.240$ & 2.560 \\
\hline 49 & $<5$ & $<5$ & 2.560 & 80 & 5.120 & 160 & $\geq 10.240$ & 80 & $\geq 10.240$ & 1.280 \\
\hline
\end{tabular}

a Títulos de anticorpos neutralizantes frente às amostras homólogas, expressos como a recíproca da maior diluição capaz de inibir a replicação viral.

${ }^{b}$ Dia da primeira imunização.

c Dia da segunda imunização.

d Dia do desafio (138 dias após a vacinação).

eAmostra não testada.

\section{Proteção fetal}

Para a avaliação da proteção fetal, as vacas foram desafiadas 104 dias após a segunda dose vacinal, pela inoculação IN de quatro amostras de vírus NCP heterólogos aos vírus vacinais (duas de BVDV-1 e duas de BVDV2). Trinta e oito dias após o desafio (176dpv) todos os animais foram submetidos ao exame da gestação por palpação retal e exame US. Todas as vacas do grupo vacinado estavam prenhes e com os fetos viáveis. Já no grupo controle não-vacinado, duas vacas haviam abortado (\#63 e 84), mas os fetos não foram encontrados. As demais vacas deste grupo apresentavam fetos viáveis. $\mathrm{O}$ exame realizado no dia 70 pós-desafio (208dpv) revelou que mais uma vaca do grupo controle havia abortado (\#58). As demais vacas do grupo controle e todas as vacinadas apresentavam fetos viáveis. No exame do dia 130 pósdesafio (268dpv), observou-se que mais uma vaca do grupo controle (\#56) e uma do grupo vacinal (\#22) haviam abortado. Aproximadamente três semanas antes do início da parição, mais uma vaca do grupo controle abortou (\#109). Não foi possível realizar a pesquisa de vírus e/ou anticorpos em nenhum dos fetos abortados neste período, pois os mesmos não foram encontrados. O resumo dos indicadores clínicos, virológicos e sorológicos de infecção fetal nos grupos vacinado e controle estão apresentados nos Quadros 2 e 3, respectivamente.

Todos os bezerros do grupo vacinado $(n=18)$, com exceção daquele abortado, nasceram saudáveis (Quadro

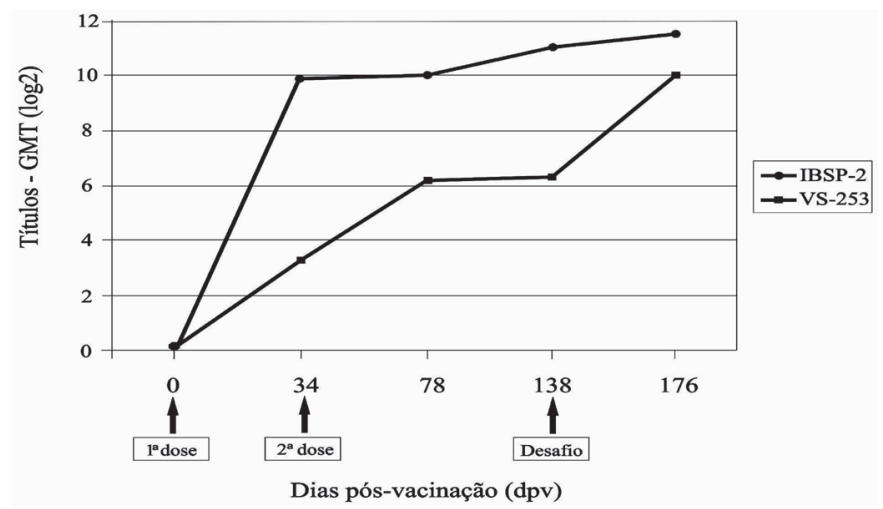

Fig.2. Evolução dos títulos de anticorpos neutralizantes frente às amostras homólogas de vírus (BVDV-1 = IBSP-2; BVDV2 = VS-253) no soro de vacas imunizadas com uma vacina experimental atenuada contra o vírus da diarréia viral bovina (BVDV). Os títulos de anticorpos neutralizantes estão expressos em médias geométricas (GMT).

2). Dezessete desses bezerros $(89,4 \%)$ nasceram negativos para vírus, como foi demonstrado pela falha em isolar vírus da capa flogística coletada logo após o nascimento, e também aos 30 dias de idade (Quadro 2). Destes, 10 não apresentavam anticorpos neutralizantes e os sete restantes foram positivos para anticorpos. Dos sete bezerros que apresentaram anticorpos, quatro haviam inadvertidamente ingerido colostro antes da coleta de sangue, o que explicaria a presença de anticorpos no soro. 
Quadro 2. Indicadores clínicos, virológicos e sorológicos de infecção fetal em vacas prenhes previamente imunizadas com uma vacina experimental atenuada e desafiadas com um pool de quatro amostras heterólogas do vírus da diarréia viral bovina (BVDV)

\begin{tabular}{|c|c|c|c|c|c|c|c|}
\hline & \multirow[t]{2}{*}{$\begin{array}{l}\text { Vaca } \\
\text { no. }\end{array}$} & \multicolumn{2}{|c|}{$\begin{array}{l}\text { Título de anticorpos } \\
\text { no dia do desafio } \\
\end{array}$} & \multirow[t]{2}{*}{$\begin{array}{l}\text { Condição } \\
\text { clínica }\end{array}$} & \multirow{2}{*}{$\begin{array}{c}\text { Vírus }^{\mathrm{b}} \\
\text { Feto/bezerro }\end{array}$} & \multirow[t]{2}{*}{$\begin{array}{c}\text { Anticorpos } \\
\text { neutralizantes }^{\mathrm{c}}\end{array}$} & \multirow[t]{2}{*}{ Observações } \\
\hline & & IBSP-2 & VS-253 & & & & \\
\hline & 10 & $\geq 10.240$ & 640 & Saudável & Negativo & $<5 /<5$ & - \\
\hline & 48 & 5.120 & 320 & Saudável & Negativo & $<5 /<5$ & - \\
\hline & 49 & $\geq 10.240$ & 80 & Saudável & Negativo & $<5 /<5$ & - \\
\hline & 12 & 1.280 & 160 & Saudável & Negativo & $<5 /<5$ & - \\
\hline & 40 & 5.120 & 160 & Saudável & Negativo & $<5 /<5$ & - \\
\hline & 17 & 5.120 & 160 & Saudável & Negativo & $<5 /<5$ & - \\
\hline Grupo & 35 & 5.120 & 20 & Saudável & Negativo & $<5 /<5$ & - \\
\hline \multirow[t]{12}{*}{ vacinado } & 23 & 5.120 & 1280 & Saudável & Negativo & $<5 /<5$ & - \\
\hline & 28 & $\geq 10.240$ & 1280 & Saudável & Negativo & $<5 /<5$ & - \\
\hline & 31 & 5.120 & 80 & Saudável & Negativo & $<5 /<5$ & - \\
\hline & 32 & 2.560 & 640 & Saudável & Negativo & $\geq 640 / \geq 640$ & - \\
\hline & 3 & 5.120 & 640 & Saudável & Negativo & 320 / $320^{d}$ & - \\
\hline & 38 & $\geq 10.240$ & 160 & Saudável & Negativo & $\geq 640 / \geq 640^{d}$ & - \\
\hline & 19 & $\geq 10.240$ & 640 & Saudável & Negativo & $\geq 640 / \geq 640^{d}$ & - \\
\hline & 45 & 2.560 & 320 & Saudável & Negativo & $160 / \geq 640$ & - \\
\hline & 16 & 5.120 & 320 & Saudável & Negativo & $\geq 640 / \geq 640$ & - \\
\hline & 5 & $\geq 10.240$ & 160 & Saudável & Negativo & $\geq 640 / \geq 640^{d}$ & - \\
\hline & 33 & $\geq 10.240$ & 80 & Saudável & Positivo & $<5 /<5$ & \\
\hline & 22 & 5.120 & 320 & Aborto & Não testada & Não testada & $\begin{array}{l}\text { Aborto diagnosticado } \\
\text { no dia } 130 \text { pós-desafio }\end{array}$ \\
\hline
\end{tabular}

a Título de anticorpos neutralizantes no soro das vacas imunizadas com a vacina experimental, no dia do desafio (138dpv).

b Pesquisa de vírus no sangue pré-colostral dos bezerros nascidos das vacas imunizadas.

c Título de anticorpos neutralizantes no soro pré-colostral dos bezerros nascidos das vacas imunizadas (BVDV-1/BVDV-2).

Título $<5$ significa que foi negativo para anticorpos neutralizantes na menor diluição de soro testada.

d Bezerro ingeriu colostro antes da coleta de sangue.

Quadro 3. Indicadores clínicos, virológicos e sorológicos de infecção fetal em vacas prenhes não-imunizadas (grupo controle) desafiadas com um pool de quatro amostras de campo do vírus da diarréia viral bovina (BVDV)

\begin{tabular}{|c|c|c|c|c|c|c|c|}
\hline & \multirow[t]{2}{*}{$\begin{array}{l}\text { Vaca } \\
\text { no. }\end{array}$} & \multicolumn{2}{|c|}{$\begin{array}{l}\text { Título de anticorpos } \\
\text { no dia do desafio }\end{array}$} & \multirow[t]{2}{*}{$\begin{array}{l}\text { Condição } \\
\text { clínica }\end{array}$} & \multirow{2}{*}{$\begin{array}{c}\text { Vírus }^{b} \\
\text { Feto/bezerro }\end{array}$} & \multirow[t]{2}{*}{$\begin{array}{c}\text { Anticorpos } \\
\text { neutralizantes }\end{array}$} & \multirow[t]{2}{*}{ Observações } \\
\hline & & IBSP-2 & VS-253 & & & & \\
\hline & 84 & $<5$ & $<5$ & Aborto & Não testada & Não testada & Aborto diagnosticado no dia 30 pós-desafio \\
\hline & 63 & $<5$ & $<5$ & Aborto & Não testada & Não testada & Aborto diagnosticado no dia 30 pós-desafio \\
\hline & 58 & $<5$ & $<5$ & Aborto & Não testada & Não testada & Aborto diagnosticado no dia 70 pós-desafio \\
\hline & 56 & $<5$ & $<5$ & Aborto & Não testada & Não testada & Aborto diagnosticado no dia 130 pós-desafio \\
\hline & 109 & $<5$ & $<5$ & Aborto & Não testada & Não testada & Abortou duas a três semanas antes do parto \\
\hline & 77 & $<5$ & $<5$ & Prematuro & Positivo & $<5 /<5$ & $\begin{array}{l}\text { Cascos malformados, morreu três dias após } \\
\text { o nascimento }\end{array}$ \\
\hline $\begin{array}{l}\text { Grupo } \\
\text { não- }\end{array}$ & 66 & $<5$ & $<5$ & Prematuro & Negativo & $e \geq 640 / e \geq 640$ & $\begin{array}{l}\text { Cascos malformados, morreu uma semana } \\
\text { após o nascimento }\end{array}$ \\
\hline \multirow[t]{10}{*}{ vacinado } & 75 & $<5$ & $<5$ & Natimorto & Negativod & Não testada & - \\
\hline & 99 & $<5$ & $<5$ & Natimorto & Não testada & Não testada & - \\
\hline & 90 & $<5$ & $<5$ & Fraco & Positivo & $<5 /<5$ & Morreu 15 dias após o nascimento \\
\hline & 80 & $<5$ & $<5$ & Saudável & Negativo & $<5 /<5$ & - \\
\hline & 102 & $<5$ & $<5$ & Saudável & Negativo & $<5 /<5$ & - \\
\hline & 101 & $<5$ & $<5$ & Saudável & Negativo & $10 / e \geq 640$ & - \\
\hline & 68 & $<5$ & $<5$ & Saudável & Positivo & $e \geq 640 / 80^{e}$ & - \\
\hline & 51 & $<5$ & $<5$ & Saudável & Positivo & $<5 /<5$ & - \\
\hline & 52 & $<5$ & $<5$ & Saudável & Positivo & $<5 /<5$ & - \\
\hline & 64 & $<5$ & $<5$ & Saudável & Positivo & $<5 /<5$ & - \\
\hline \multirow{2}{*}{\multicolumn{8}{|c|}{$\begin{array}{l}\text { Título de anticorpos neutralizantes no soro das vacas do grupo controle no dia do desafio (138dpv). } \\
\text { Pesquisa de vírus no sanque pré-colostral dos bezerros nascidos das vacas do grupo controle. }\end{array}$}} \\
\hline & & & & & & & \\
\hline \multicolumn{8}{|c|}{$\begin{array}{l}\text { c Título de anticorpos neutralizantes no soro pré-colostral dos bezerros nascidos das vacas do grupo controle (BVDV-1/BVDV-2). Título } \\
<5 \text { significa que foi negativo para anticorpos neutralizantes na menor diluição de soro testada. }\end{array}$} \\
\hline
\end{tabular}


Um bezerro (vaca \#33) nasceu negativo para anticorpos e positivo para vírus. Um novo teste de isolamento viral da capa flogística realizado aos 30 dias de idade confirmou o caráter de infecção persistente neste animal.

No grupo controle $(n=18)$, apenas três bezerros $(16,6 \%)$ nasceram saudáveis e negativos para vírus (\#80, 102 e 101). Outros sete bezerros $(38,8 \%)$ nasceram positivos para vírus $(\# 77,90,68,51,52,64,108)$. Cinco destes bezerros nasceram com aparência saudável e sobreviveram $(27,7 \%)$; os outros dois morreram dias após o nascimento: um era prematuro e outro havia nascido fraco. Um novo teste de isolamento viral realizado aos 30-60 dias de idade também resultou positivo, confirmando o caráter persistente da infecção nesses animais. Três bezerros (\#66, 75 e 99) nasceram mortos, sendo que um (\#66) apresentou sinais de prematuridade. Um bezerro natimorto (\#99) não foi avaliado quanto à presença do vírus, pois foi encontrado autolisado (Quadro 3).

Comparando-se os grupos vacinados e controle, verificou-se que o número de bezerros viáveis e negativos para vírus, utilizados como indicadores de proteção fetal, foram superiores dentre os vacinados $(89,4 \%$ [17/19] versus $16,6 \%[3 / 18])$.

\section{DISCUSSÃO}

Apesar da diversidade dos vírus e da alta dose viral utilizada no desafio - pouco provável de ocorrer em condições naturais - a vacina experimental conferiu proteção fetal em pelo menos $90 \%$ (17/19) das fêmeas vacinadas, sendo que em apenas um bezerro $(5,2 \%)$ foi possível demonstrar infecção fetal. Essa vacina já havia sido previamente avaliada, demonstrando ser capaz de conferir proteção fetal em ovelhas prenhes (Brum et al. 2002), além de ser suficientemente atenuada e altamente imunogênica para bovinos (Lima et al. 2004). Assim, essa formulação vacinal e o protocolo de vacinação utilizado apresentamse como alternativas promissoras para a redução das perdas reprodutivas causadas pela infecção pelo BVDV no Brasil. Essa utilização, no entanto, depende ainda de testes adicionais de segurança e eficácia, além do eventual licenciamento do imunógeno para a produção e comercialização.

A iniciativa de se produzir uma vacina experimental atenuada contra o BVDV surgiu da constatação da grande variabilidade antigênica dos isolados de BVDV circulantes no país (Botton et al. 1998), e de que as vacinas comerciais então existentes no comércio nacional induziam baixos títulos de anticorpos neutralizantes, provavelmente incompatíveis com proteção clínica e/ou fetal (Vogel et al. 2001, Lima et al. 2005). Essas vacinas continham apenas cepas de BVDV-1, de origem européia ou norteamericana. A identificação dos vírus do genótipo 2 (BVDV2) associados com doença severa nos Estados Unidos e Canadá na década de 90 tornou mandatória a inclusão de vírus dos dois genótipos nas vacinas (Ridpath 2004). Assim, com base em relatos que demonstraram a circulação de vírus dos dois genótipos no Brasil (Botton et al.
1998, Flores et al. 2002), além dos testes com vacinas comerciais (Vogel et al. 2001, Lima et al. 2005), decidiuse incluir vírus representativos de BVDV-1 e BVDV-2 na formulação da vacina experimental.

Os vírus vacinais foram obtidos por múltiplas passagens $(n=30)$ em cultivo celular, associado com clonagem biológica e mutagênese física (radiação ultravioleta) (Brum et al. 2002) e foram previamente testados em relação a imunogenicidade e proteção fetal em ovelhas prenhes (Brum et al. 2002) e atenuação e imunogenicidade em bezerros (Lima et al. 2004). O presente experimento foi delineado para testar a eficácia dos vírus vacinais em conferir proteção fetal em vacas prenhes, mantidas a campo e desafiadas com uma suspensão viral contendo uma alta dose de vírus heterólogos dos dois genótipos.

A indução de proteção fetal frente a desafio com vírus de campo se constitui no principal objetivo das vacinas contra o BVDV, por reduzir as perdas reprodutivas, mas, principalmente, por impedir a geração de animais persistentemente infectados (Ridpath 2005, Kelling 2004). No entanto, após quase cinco décadas de pesquisa e desenvolvimento esse objetivo segue como um grande desafio, pois até o presente nenhuma vacina contra o BVDV demonstrou eficácia total na prevenção da infecção fetal. A falha das vacinas em proteger os fetos da infecção tem sido demonstrada tanto por estudos experimentais (Brownlie et al. 1995, Cortese et al. 1998, Bruschke et al. 1999, Beer et al. 2000, Kovács et al. 2003, Fairbanks et al. 2004, Brock et al. 2006, Ellsworth et al. 2006, Ficken et al. 2006, Grooms et al. 2007) como por observações a campo (Dubovi 1992, Kelling 2004).

Diferentes níveis de proteção têm sido obtidos com o uso de vários tipos de vacinas (inativadas, atenuadas, de subunidades), doses e formulações (mono, di, tri e tetravalentes [BVDV-1a, 1b + BVDV-2a, 2b]) e protocolos de vacinação (Brownlie et al. 1995, Cortese et al. 1998, Bruschke et al. 1999, Beer et al. 2000, Kovács et al. 2003, Fairbanks et al. 2004, Brock et al. 2006, Ellsworth et al. 2006, Ficken et al. 2006, Grooms et al. 2007). Outras variáveis que podem influenciar os resultados desses testes incluem: i.) a forma de desafio (inoculação versus exposição a animais $\mathrm{PI}$ ); ii.) dose e identidade (variabilidade antigênica) dos vírus utilizados no desafio; iii.) tempo após a vacinação em que o desafio é realizado; e iv.) indicadores utilizados para avaliar proteção fetal. No entanto, independentemente do tipo e protocolo de vacinação, esses estudos têm demonstrado como regra que, mesmo sob condições tidas como ótimas, a proteção fetal é freqüentemente incompleta (Van Oirschot et al. 1999, Kelling 2004). As falhas de proteção fetal demonstradas pelos estudos experimentais podem explicar a contínua produção de animais $\mathrm{PI}$, mesmo em rebanhos adequadamente vacinados (Dubovi 1992, Kelling 2004). Da mesma forma, essas falhas vacinais servem como um desafio para a indústria de vacinas prosseguir no intento de produzir vacinas mais eficazes.

No presente estudo, a vacinação em duas doses - pro- 
tocolo testado anteriormente com sucesso (Brum et al. 2002, Lima et al. 2004) - induziu títulos médios e altos de anticorpos na grande maioria dos animais, com poucas exceções (Quadro 1). Considerando-se o título de 80, sugerido como mínimo para conferir proteção clínica (Dubovi 1992, Ridpath 2005), apenas uma vaca (\#35) apresentava título inferior, frente ao BVDV-2. Todos os demais animais desenvolveram títulos iguais ou superiores a 80 frente ao BVDV-2 e títulos muito altos (iguais ou superiores a 2.560) frente ao BVDV-1.

No dia do desafio (dia 138pv), $100 \%$ das vacas apresentavam títulos iguais ou maiores que 2.560 contra o BVDV-1 e 94,7\% apresentavam títulos > 80 frente ao BVDV-2. Em geral, o soro da maioria dos animais reagiu em títulos muito superiores frente ao BVDV-1 do que contra o BVDV-2. Esse achado já havia sido relatado anteriormente (Brum et al. 2002, Lima et al. 2004) e provavelmente reflete uma maior capacidade replicativa in vivo da cepa vacinal de BVDV-1. Outro achado sorológico interessante, também já relatado anteriormente, foi a grande variação individual dos títulos de anticorpos induzidos pela vacinação (Vogel et al. 2001, Brum et al. 2002, Lima et al. 2004). Em resumo, esses resultados demonstraram a capacidade da vacina experimental em induzir títulos neutralizantes de grande magnitude, na grande maioria dos animais imunizados. Além disso, os títulos induzidos pela vacina experimental foram muito superiores aos títulos produzidos pela imunização com vacinas comerciais inativadas (Vogel et al. 2001, Lima et al. 2005).

A possível excreção dos vírus vacinais não foi monitorada, como em estudos anteriores (Brum et al. 2002, Lima et al. 2004). No entanto, a ausência de sinais clínicos nos animais após a vacinação indica que os vírus vacinais são suficientemente atenuados, conforme observação anterior em bezerros (Lima et al. 2004). Da mesma forma, a ausência de soroconversão nos animais controles mantidos juntos com os vacinados indica que esses vírus provavelmente não são excretados pelos animais vacinados em quantidade suficiente que resulte em transmissão. A possível transmissão dos vírus vacinais aos fetos também não foi avaliada, como em um estudo em ovelhas prenhes (Brum et al. 2002). Naquele estudo, os vírus vacinais foram transmitidos aos fetos ovinos, demonstrando que um futuro uso destes vírus vacinais deve ser acompanhado de estritas recomendações para evitar a sua administração a fêmeas prenhes. Estudos semeIhantes devem ser realizados em vacas prenhes, para se avaliar detalhadamente os riscos associados com o uso da vacina experimental nesta categoria de animais.

O desafio utilizado no presente estudo foi planejado para testar objetivamente a capacidade protetora da vacina experimental. Para tal, foram utilizados quatro isolados brasileiros antigenicamente diferentes (dois de BVDV1; dois de BVDV-2) em uma dose total de $10^{7,1} \mathrm{DICC}_{50}$. Dentre os estudos vacinais disponíveis na literatura, nenhum utilizou esse número de amostras heterólogas ou uma dose viral tão elevada no desafio. A maioria dos es- tudos de eficácia vacinal tem utilizado os vírus homólogos (Beer et al. 2000), vírus do mesmo genótipo do vírus vacinal (Cortese et al. 1998), ou um vírus de cada genótipo, separadamente (Kovács et al. 2003, Fairbanks et al. 2004, Brock et al. 2006, Ficken et al. 2006). Assim, poucos estudos têm utilizado vários vírus heterólogos concomitantemente no desafio (Zimmer et al. 2002). Outro aspecto controverso diz respeito à dose de vírus adequada para o desafio, e a maioria dos estudos têm inoculado o vírus em títulos entre $10^{4.5}$ e $10^{5} \mathrm{DICC}_{50}$ (Frey et al. 2002, Ficken et al. 2006). Uma forma alternativa de desafio - que mais se assemelha às condições naturais - seria a exposição dos animais vacinados a animais PI (Ellsworth et al. 2006, Grooms et al. 2007). De qualquer forma, o desafio utilizado no presente estudo demonstrou ser eficiente em produzir infecção e perdas fetais em grande parcela dos animais controle. A soroconversão observada nos animais controle - e também nos vacinados - após o desafio também demonstrou que esses vírus replicaram com eficiência nos animais inoculados.

Dentre os animais vacinados, podem-se identificar vários grupos, de acordo com os indicadores de proteção (Quadro 2). Um primeiro grupo abrange as dez vacas que pariram fetos saudáveis, negativos para vírus e para anticorpos. Esses indicadores demonstram a ocorrência de proteção total ao desafio. Um segundo grupo é composto por sete vacas que pariram fetos saudáveis, negativos para vírus, porém positivos para anticorpos. Do ponto de vista prático, estes animais poderiam ser incluídos no grupo considerado protegido, pois eram saudáveis e negativos para vírus ao nascimento. No entanto, a presença de anticorpos no soro destes bezerros recém-nascidos merece consideração. Em quatro casos, é provável que os anticorpos tenham sido adquiridos pela ingestão de colostro, pois os bezerros foram encontrados várias horas após o nascimento. Em outros três, no entanto, o soro aparentemente foi coletado previamente a ingestão do colostro. Nestes casos, não se pode descartar a hipótese de que os fetos tenham sofrido infecção pelos vírus do desafio, ou seja, não foram protegidos pela resposta imune das mães. É possível que a quantidade de vírus que conseguiu alcançar e infectar os fetos tenha sido muito pequena (em virtude da presença de anticorpos neutralizantes no sangue materno) e insuficiente para levar a morte fetal. Assim, o sistema imunológico dos fetos teria respondido e eliminado a infecção, o que explicaria a presença de anticorpos neutralizantes no sangue ao nascimento (Stokstad \& Loken, 2002). Se este foi realmente o caso, poderia-se considerar que houve proteção parcial.

Um bezerro filho de uma vaca imunizada (\#33) nasceu saudável, porém positivo para vírus e negativo para anticorpos $(5,2 \%)$. Um exame posterior aos 30 dias de idade confirmou o caráter de infecção persistente, demonstrando a falha da vacinação em prevenir a infecção fetal. Uma provável causa desta falha foi o alto título de vírus utilizado no desafio, além da inclusão de quatro vírus 
antigenicamente diferentes no inóculo. A maioria dos estudos de proteção vacinal contra o BVDV tem utilizado vírus em títulos próximos a $10^{5} \mathrm{DICC}_{50}$ no desafio (Frey et al. 2002, Ficken et al. 2006). O presente estudo utilizou no desafio um pool de vírus, antigenicamente diferentes entre si e dos vírus vacinais, em dose total próxima aos $10^{7} \mathrm{DICC}_{50}$. Desafio com quantidades de vírus nesta magnitude são improváveis de ocorrer na natureza, pois os animais $\mathrm{PI}$, que são as principais fontes de vírus, excretam o agente em secreções em títulos raramente superiores a $10^{5} \mathrm{DICC}_{50} / \mathrm{ml}$ (Brock et al. 1991). Nesse caso, uma forma mais adequada de desafio seria a exposição dos animais vacinados a animais $\mathrm{PI}$, como tem sido realizado em alguns estudos (Ellsworth et al. 2006, Grooms et al. 2007). De qualquer forma, é provável que desafios com carga viral desta magnitude dificilmente ocorram em condições naturais.

Embora o vírus presente no bezerro PI não tenha sido identificado ou tipificado, é provável que seja um dos BVDV-2 presentes no inóculo. O título de anticorpos séricos na vaca \#33 contra o BVDV-2 no dia do desafio (80) era muito inferior ao título frente ao BVDV-1 (10.240). Se esse foi realmente o caso, a infecção fetal teria ocorrido frente a um título de 80 - um dos menores desenvolvidos pelos animais vacinados - e que é considerado um título mínimo quando se refere à proteção clínica contra o BVDV (Dubovi 1992). Títulos de 320 ou mais seriam provavelmente pouco compatíveis com infecção fetal e, conseqüentemente, falha vacinal.

Não foi possível determinar se o abortamento da vaca \#22 foi conseqüência da infecção fetal, pois o feto abortado não foi encontrado e não pode ser testado para a presença de vírus ou anticorpos. No entanto, os títulos de anticorpos de 5.120 (BVDV-1) e 320 (BVDV-2) sugerem que a infecção fetal dificilmente ocorreria neste animal, o que favorece a hipótese de aborto não relacionado com a infecção pelo BVDV.

Dez vacas do grupo controle apresentaram perdas reprodutivas durante a gestação (abortos) ou nas proximidades do parto (prematuridade, natimortalidade, inviabilidade do recém-nascido) (Quadro 3). Infelizmente, a maioria desses fetos não pode ser examinada para a presença de vírus e/ou de anticorpos. Em apenas dois deles (\#77 e 90) foi possível demonstrar a presença do vírus, o que confirmou a infecção fetal. A ocorrência dessas perdas quase que exclusivamente no grupo controle, no entanto, indica que provavelmente estão relacionadas com a infecção. Abortos em qualquer fase da gestação, natimortalidade e o nascimento de bezerros inviáveis estão entre as conseqüências da infecção de vacas prenhes com o BVDV (Grooms 2007). Outros cinco bezerros (\#68, 51, 52, 64 e 108) apresentaram indicativo de infecção ao nascimento, pelo isolamento do vírus da capa flogística. O caráter persistente da infecção foi confirmado pelo isolamento viral realizado novamente aos 30 dias de idade. A produção de bezerros PI é uma das características da infecção de fetos entre 40 e 120 dias de gesta- ção pelo BVDV, e possui um significado muito importante na epidemiologia da infecção (Houe 1995). Seria de especial interesse determinar se mais de um dos vírus utilizados no desafio está presente nos bezerros PI, e assim se determinar se é possível o estabelecimento de infecção persistente por mais de um vírus, concomitantemente.

Em resumo, a vacinação conferiu proteção fetal (do ponto de vista clínico e virológico) em 17 de 19 vacas $(89,4 \%)$. Essa proteção ocorreu mesmo frente a um desafio altamente improvável de ocorrer em condições naturais (um pool de quatro vírus antigenicamente diferentes, em dose total de $\left.10^{7} \mathrm{DICC}_{50}\right)$. Em três bezerros clinicamente saudáveis e livres de vírus, a possibilidade de infecção fetal não pode ser descartada devido a presença de anticorpos presente no soro pré-colostral. Uma vaca abortou, mas a causa do aborto não pôde ser atribuída à infecção fetal. Infecção fetal (e, por conseguinte, falha vacinal) foi demonstrada em apenas um bezerro do grupo vacinado $(5,2 \%)$. A mãe deste bezerro, no entanto, apresentava um título de anticorpos (contra o BVDV-2) no limite mínimo considerado protetor (80) e um dos menores induzidos pela vacinação no presente estudo. Esses resultados sugerem que títulos mais altos (em nível individual) e homogêneos (em nível de rebanho) - provavelmente acima de 160-320 - são necessários e devem ser almejados no intuito de se obter proteção fetal completa contra o BVDV. A grande variabilidade antigênica do vírus, no entanto, continua a representar um importante obstáculo à obtenção de níveis completos de proteção.

Estudos futuros com essa vacina experimental devem incluir: i.) avaliação de inocuidade para fêmeas gestantes e seus fetos; ii.) testes de imunogenicidade com um número maior de animais a campo, em rebanhos soronegativos e soropositivos; iii.) avaliação da dose viral mínima necessária para induzir uma resposta sorológica em níveis mais homogêneos e adequados; iv.) testes de proteção com desafio por exposição a animais PI; v.) testes de estabilidade genética; e vi.) avaliação de viabilidade após liofilização, armazenamento e reconstituição, entre outros.

\section{REFERÊNCIAS}

Baker J.C. 1995. The clinical manifestations of bovine viral diarrhea infection. Vet. Clin. North Am. 11(3):425-445.

Beer M., Hehnen H.R., Wolfmeyer A., Poll G., Kaaden O.R. \& Wolf G. 2000. A new inactivated BVDV genotype I e II vaccine: An immunisation and challenge study with BVDV genotype I. Vet. Microbiol. 77(1/2):195208.

Bolin S. 1995. Control of bovine viral diarrhea virus infection by use of vaccination. Vet. Clin. North Am. 11(3):615-626.

Botton S.A., Silva A.M., Brum M.C.S., Flores E.F. \& Weiblen R. 1998. Antigenic characterization of Brazilian bovine viral diarrhea virus isolates by monoclonal antibodies and cross-neutralization. Braz. J. Med. Biol. Res. 31(11):1429-1438.

Brock K.V., Redman D.R., Vickers M.L. \& Irvine N.E. 1991. Quantitation of bovine viral diarrhea virus in embryo transfer flush fluids collected from a persistently infected heifer. J. Vet. Diagn. Invest. 3:99-100.

Brock K.V., McCarty K., Chase C.C. \& Harland R. 2006. Protection against 
fetal infection with either bovine viral diarrhea virus type 1 or type 2 using a noncytopathic modified-live virus vaccine. Vet. Ther. 7(1):2734.

Brownlie J., Clarke M.C., Hooper L.B. \& Bell G.D. 1995. Protection of the bovine fetus from bovine viral diarrhea virus by means of a new inactivated vaccine. Vet. Rec. 137(3):58-62.

Brum M.C.S., Weiblen R., Flores E.F., Pituco E.M., Tobias F.L. \& Winkelmann E.R. 2002. Proteção fetal frente a desafio com o vírus da Diarréia Viral Bovina (BVDV) em ovelhas imunizadas com duas amostras de vírus modificadas experimentalmente. Pesq. Vet. Bras. 22(2):64-72.

Bruschke C.J., Van Oirschot J.T. \& Van Rijn P.A. 1999. An experimental multivalent bovine virus diarrhea virus E2 subunit vaccine and two experimental conventionally inactivated vaccines induce partial fetal protection in sheep. Vaccine 17(15/16):1983-1991.

Cortese V.S., Grooms D.L., Ellis J., Bolin S.R., Ridpath J.F. \& Brock K.V. 1998. Protection of pregnant cattle and their fetuses against infection with bovine viral diarrhea virus type 1 by use of a modifiedlive virus vaccine. Am. J. Vet. Res. 59(11):1409-1413.

Cortez A., Heinemann M.B., Castro A.M.M.G., Soares R.M., Pinto A.M.V., Alfieri A.A., Flores E.F., Leite R.C. \& Richtzenhain L.J. 2006. Genetic characterization of Brazilian bovine viral diarrhea virus isolates by partial nucleotide sequencing of the 5'-UTR region. Pesq. Vet. Bras. 26(4):211-216.

Donis R.O. 1995. Molecular biology of bovine viral diarrhea virus and its interactions with the host. Vet. Clin. North Am. 11(3):393-423.

Dubovi E.J. 1992. Genetic diversity and BVD virus. Comp. Immun. Microbiol. Infect. Dis. 15(3):155-162.

Ellsworth M.A., Fairbanks K.K., Behan S., Jackson J.A., Goodyear M., Oien N.L., Meinert T.R. \& Leyh R.D. 2006. Fetal protection following exposure to calves persistently infected with bovine viral diarrhea virus type 2 sixteen months after primary vaccination of the dams. Vet. Ther. 7(3):295-304.

Fairbanks K.K., Rinehart C.L., Ohnesorge W.C., Loughin M.M. \& Chase C.C. 2004. Evaluation of fetal protection against experimental infection with type 1 and type 2 bovine viral diarrhea virus after vaccination of the dam with a bivalent modified-live virus vaccine. J. Am. Vet. Med. Assoc. 225(12):1898-1908.

Ficken M.D., Ellswoth M.A. \& Tucker C.M. 2006. Evaluation of the efficacy of a modified-live combination vaccine against bovine viral diarrhea virus types 1 and 2 challenge exposures in one-year duration-ofimmunity fetal protection study. Vet. Ther. 7(3):283-294.

Flores E.F., Ridpath J.F., Weiblen R., Vogel F.S.F. \& Gil L.H.V.G. 2002. Phylogenetic analysis of Brazilian bovine viral diarrhea virus type 2 (BVDV-2) isolates: evidence for a subgenotype within BVDV-2. Virus Res. 87:51-60.

Flores E.F., Weiblen R., Vogel F.S.F., Roehe P.M., Alfieri A.A. \& Pituco E. M. 2005. A infecção pelo vírus da Diarréia Viral Bovina (BVDV) no Brasil: histórico, situação atual e perspectivas. Pesq. Vet. Bras. 25:25-134.

Frey H.R., Eicken K., Grummer B., Kenklies S., Oguzoglu T.C. \& Moenning V. 2002. Foetal protection against bovine viral diarrhea virus after two-step vaccination. J. Vet. Med. B. 49:489-493.

Fulton R.W. \& Burge L.J. 2001. Bovine viral diarrhea virus types 1 and 2 response in calves receiving modified live virus or inactivated vaccines. Vaccine 19:264-274.

Fulton R.W., Ridpath J.F., Confer A.W., Saliki J.T., Burge L.T. \& Payton M.E. 2003. Bovine viral diarrhoea virus antigenic diversity: impact on disease and vaccination programmes. Biol. 31:89-95.
Grooms D.L., Bolin S.R., Coe P.H., Borges R.J. \& Coutu C.E. 2007. Fetal protection against exposure to bovine viral diarrhea virus following administration of a vaccine containing an inactivated bovine viral diarrhea virus fraction to cattle. Am. J. Vet. Res. 68(12):14171422.

Horzinek M.C. 1991. Pestivirus: taxonomic perspectives. Arch. Virol. (Suppl.3):1-5.

Houe H. 1995. Epidemiology of bovine viral diarrhea virus. Vet. Clin. North Am. 11(3):521-548.

Kalaycioglu A.T. 2007. Bovine viral diarrhoea virus (BVDV) diversity and vaccination: A review. Vet. Quart. 29(2):60-67.

Kelling C.L. 2004. Evolution of bovine viral diarrhea virus vaccines. Vet. Clin. North Am. 20:115-129.

Kovács F., Magyar T., Rinehart C., Elbers K., Schlesinger K. \& Ohnesorge,W.C. 2003. The live attenuated bovine viral diarrhea virus components of a multivalent vaccine confer protection against fetal infection. Vet. Microbiol. 96(2):117-131.

Lima M., Flores E.F., Weiblen R., Vogel F.S.F. \& Arenhart S. 2004. Caracterização de amostras atenuadas do vírus da Diarréia Viral Bovina (BVDV) tipos 1 e 2 para uso em vacinas. Pesq. Vet. Bras. 24(1):35-42.

Lima M., Vogel F.S.F., Flores E.F. \& Weiblen R. 2005. Anticorpos neutralizantes contra o vírus da Diarréia Viral Bovina (BVDV): comparação entre um imunógeno experimental atenuado e três vacinas comerciais inativadas. Ciência Rural 35(1):230-234.

Lindenbach B.D. \& Rice C.M. 2001. Flaviviridae: The viruses and their replication, p.991-1042. In: Knipe D.M. et al. (Ed.), Fields Virology. Lippincot Williams and Williams, Philadelphia, PA., USA.

McClurkin A.W., Littledike E.T., Cutlip R.C., Frank G.H., Coria M.F. \& Bolin S.R. 1984. Production of cattle immunotolerant to BVD virus. Can. J. Comp. Med. 48:156-161.

Pellerin C., Hurk J., van den Lecomte J. \& Tussen P. 1994. Identification of a new group of bovine viral diarrhea virus strains associated with severe outbreaks and high mortalities. Virology 203(2):260-268.

Reed L. \& Muench H. 1938. A simple method of stimating fifty percent endpoints. Am. J. Hyg. 18:493-494.

Ridpath J.F. 2005. Practical significance of heterogeneity among BVDV strains: impact of biotype and genotype on U.S. control programs. Prev. Vet. Med. 72(1/2):17-30.

Stokstad M. \& Loken T. 2002. Pestivirus in cattle: experimentally induced persistent infection in calves. J. Vet. Med. B. 19(10):494-501.

Thrusfield M. 1986. Serological epidemiology, p.175-185. In: (Ed.), Veterinary Epidemiology. Butterworth, London.

Van Oirschot J.T., Bruschke C.J.M. \& Van Rijn P.A. 1999. Vaccination of cattle against bovine viral diarrhoea. Vet. Microbiol. 64:169-183.

Vogel F.S.F., Scherer C.F.C., Weiblen R., Flores E.F., Lima M. \& Kunrath C.F. 2001. Resposta sorológica e avaliação de proteção fetal em oveIhas prenhes vacinadas contra o vírus da diarréia viral bovina (BVDV). Ciência Rural 31(5):831-838.

Vogel F.S.F., Flores E.F., Weiblen R., Mayer S.V., Quadros V.L. \& Oldoni I. 2002. Magnitude, duração e especificidade da resposta sorológica em bovinos vacinados contra o vírus da diarréia viral bovina. Ciência Rural 32(1):83-89.

Zimmer G.M., Wentink G.H., Bruschke C., Westenbrink F.J., Brinkhof J. \& de Goey I. 2002. Failure of foetal protection after vaccination against an experimental infection with bovine viral diarrhea virus. Vet. Microbiol. 89:255-265. 